East African Medical Journal Vol. 87 No. 4 April 2010

BONE METABOLISM IN HEALTHY AMBULATORY CONTROL PRE-MENOPAUSAL WOMEN AND IN EPILEPTICS ON ANTI-CONVULSANT DRUGS

J.K. Kwasa, MBChB, MMed, Physician, Kenya Medical Research Institute, P.O. Box 52535 - 00200, Nairobi, Kenya, A. Amayo, MBChB, MMed, Senior Lecturer, Department of Human Pathology, P.M. Ndavi, MBChB, MMed (Obs \& Gynae), Associate Professor, Department of Obstetrics and Gynaecology and T.O.O. Kwasa, MBChB, MMed, Senior Lecturer, Department of Clinical Medicine and Therapeutics, College of Health Sciences, University of Nairobi, P.O. Box 19676 - 00202, Nairobi, Kenya

Request for reprints to: Dr. J. K. Kwasa, P.O. Box 52535-00200, Nairobi, Kenya

\title{
BONE METABOLISM IN HEALTHY AMBULATORY CONTROL PRE- MENOPAUSAL WOMEN AND IN EPILEPTICS ON ANTI-CONVULSANT DRUGS
}

\author{
J.K. KWASA, A. AMAYO, P.M. NDAVI and T.O.O. KWASA
}

\begin{abstract}
Background: Long term anti-epileptic drug use causes multiple abnormalities in calcium and bone metabolism that have been documented in both institutionalised and ambulatory patients.

Objective: To assess bone metabolism in ambulatory females of reproductive age, on antiepileptic drugs.

Design: Cross sectional comparative study.

Subjects: Ambulatory females in reproductive age group with epilepsy and on regular follow up were compared to healthy females of similar ages not on any treatment.

Results: The mean duration of treatment for epilepsy was eight years $( \pm 6.3)$. Majority of the patients were on enzyme inducing drugs like phenobarbital, phenytoin, carbamazepine and valproate, either alone or in combination with non-enzyme inducers like lamotrigine $\mathbf{( 9 8 . 2 \% )}$ ). There was a significantly lower mean serum calcium and a higher alkaline phosphatase level among the patients $(\mathrm{P}=0.002$ and 0.0001 respectively) than among the comparators. The urinary marker of bone loss (mean urine calcium excretion) was also significantly raised among the patients $(P=0.003)$. The mean lumbar BMDT-score results were not significantly different in the two groups.

Conclusions: Long-term anti-epileptic drug use significantly affects biochemical parameters of bone metabolism. These effects on bone biochemistry markers were not reflected in lumbar spine BMD in this study.
\end{abstract}

\section{INTRODUCTION}

Epilepsy is a common neurological condition affecting one in every 100 individuals, both children and adults. Although most people with epilepsy become seizure free with appropriate therapy, $30 \%$ to $40 \%$ of patients will continue to have seizures despite the use of anti-epileptic drugs (AEDs) either alone or in combination (1).

Prior to 1993, the choice of anti-convulsant medication was limited to the "older" anti-epileptic drugs: phenobarbital, phenytoin, carbamazepine, valproate and primidone. Since 1993, eight new medications have been approved by the US Food and Drug Administration (FDA), expanding treatment options. These are felbamate, gabapentin, lamotrigine, topiramate, tiagabine, levetiracetam, oxcarbazepine and zonisamide. The newer anti-convulsants offer the potential advantages of fewer drug interactions, unique mechanisms of action, and a broader spectrum of activity (2).
In women, seizures and some anti-epileptic drugs can compromise reproductive health, carbohydrate and bone metabolism (3). As a general rule, the "older" drugs (see above) are associated with a worse side-effect profile than the newer anti-epileptics. The drugs most commonly associated with altered bone metabolism and decreased bone density are inducers of the cytochrome P450 enzyme system like phenytoin, carbamazepine, primidone and phenobarbital. Women using these drugs are at a higher risk for bone disorders such as osteopenia, osteomalacia and fractures.

These bone changes have been noted as early as six months to one year into therapy (4). It is worth noting that in the local set-up, these "older" drugs are the most frequently used, due to their favourable pricing (5-7).

Possible mechanisms of AED associated bone disease: Theories proposed include Hepatic induction of the cytochrome P450 enzyme system leading to increased 
catabolism of vitamin D, direct effect on bone cells, hyperparathyroidism, calcitonin deficiency and even a supposed decrease in intestinal calcium absorption $(5,8-10)$.

As there is already documented osteopenia of normally menstruating, pre-menopausal women in our set-up (11), long term anti-convulsants could significantly worsen this prevalence. No studies had been done locally, and indeed, no studies had been published from Africa, to describe the effect of longterm anti-epileptic drug use on women's bone health.

We conducted this study to assess the effects of anti-epilepticdrugsonbonemetabolism in ambulatory females of reproductive age attending neurology clinic at a referral hospital in Kenya. This was donebyblood, urine and radiographic markers of bone turnover.

\section{MATERIALS AND METHODS}

This was a cross-sectional comparative study in which women of reproductive age using anti-convulsants for more than one year, were compared to women in reproductive age who had not used anti-convulsants or any other drugs known to affect bone health (Healthy ambulant controls). Reproductive age was defined as age 15 to 49 years.

From September 2005 to October 2006, 57 patients and 53 controls were recruited into the study. The patients were randomly selected each week from the Kenyatta National Hospital Neurology clinic until the desired sample size was achieved. The controls were also recruited weekly and were sourced from patient escorts.

Upon obtaining consent, a screening questionnaire and a study proforma was filled out. Exclusion criteria included patients known to have had a history of other disease affecting bone health, current pregnancy, patients with prior history of bone fractures in the preceding one year, patients who had been bedridden, patients with recent history of diarrhoea and / or malabsorption or patients known to be or have been on drugs affecting bone metabolism. A detailed dietary history was not taken due to the difficulty in quantifying calcium levels in mostlocally available foods.

The patients and controls were all clinically evaluated by way of history and physical examination. All subjects underwent biochemical tests to ascertain markers of bone health. Serum calcium, phosphate, albumin, creatinine, alkaline phosphatase and urine calcium was assessed which were analysed using the Olympus AU 400 autoanalyser. The urinary calcium excretion was calculated using the corrected serum calcium.

A total of 24 subjectsineach groupwere randomly selected by weekly recruitment, and underwent CT scan Bone Mineral Density (BMD) assessment at the lumbar spine. Each week, two subjects in each group was selected by a randomly generated number system to go for the BMD assessment. A T-score below -2.5 Standard Deviations (SD) was considered diagnostic of osteoporosis, whereas a T-score between -1 and $-2.5 \mathrm{SD}$ was diagnostic of osteopenia.

Statistical analysis of data was undertaken using the Statistical Package for the Social Sciences (SPSS) version 11.5. Descriptive statistics such as means, medians and standard deviation were determined where applicable. Comparison of results using Odds Ratio with a 95\% Confidence Interval was done. To assess the significance of differences in continuous data, the t-test was used. P-values of $<0.05$ was considered significant.

Ethical approval to carry out this study was obtained from the Kenyatta National Hospital Ethics and Research Committee and patients were enrolled for the study only after giving informed written consent.

\section{RESULTS}

The baseline characteristics of the two groups were similar as shown in Table 1 . The mean age, age at menarche and Body Mass Index (BMI) which are known to affect bone status, were not significantly different between the groups.

Table 1

Baseline characteristics of patients and controls

\begin{tabular}{lllc}
\hline Characteristic & Patients $(\mathrm{n}=57)$ & Controls $(\mathrm{n}=53)$ & P-value \\
\hline Age in years & & & \\
$\quad$ Mean $( \pm$ SD) & $26.4 \pm 7.7$ & $28.7 \pm 9.3$ & 0.2 \\
$\quad$ Median (range) & $26(15-45)$ & $25(15-49)$ & \\
Age at menarche (years) & & & 0.06 \\
$\quad$ Mean \pm SD) & $13.96 \pm 1.9$ & $15.26 \pm 4.4$ & \\
$\quad$ Median (range) & $14.8(10-16)$ & & 0.09 \\
BMI $\left(\mathrm{kg} / \mathrm{m}^{2}\right)$ & $23.4 \pm 3.3$ & $24.6 \pm 3.6$ & \\
$\quad$ Mean $( \pm$ SD) & $22.6(16-30)$ & $24.8(17-32)$ & \\
$\quad$ Median (range) & & & \\
\hline
\end{tabular}


Majority of patients (52.6\%) had partial seizures, and most patients $(75.4 \%)$ were on a single drug regimen. Many patients $(73.6 \%)$ were using drugs broadly classified as enzyme inducers (carbamazepine, phenytoin or phenobarbitone) while about a quarter of the patients were on a combination of both enzyme inducers and non-enzyme inducers (including valproate and clonazepam).

The mean duration of therapy was $8.8( \pm 6.3)$ years with a median of seven years (range 1-25). Seizure control was mostly inadequate with $53 \%$ having poor seizure control (defined as more than two seizures in prior six months).

The patientshad significantly lower calciumlevels, and higher alkaline phosphatase and urinary calcium excretion than the controls as shown in Table 2. drugs showed a significant reduction in biochemical indices of bone mineralisation, specifically serum calcium, compared to controls. The patients also showed an increase in biochemical markers of bone turnover, specifically serum alkaline phosphatise, urine calcium creatinine ratio and urinary excretion of calcium, over the controls. This difference was not duplicated in the radiological marker of bone health, bone mineral density.

A slight majority of patients were classified as having partial seizures. This encompassed the entities of simple partial, complex partial and partial with secondary generalisation. Munyoki et al. (14) in his assessment of epilepsy in a malaria endemic region in Kenya, also found partial seizures to be the most prevalent.

Table 2

Laboratory characteristics of the sample

\begin{tabular}{lccc}
\hline $\begin{array}{l}\text { Laboratory } \\
\text { characteristic }\end{array}$ & $\begin{array}{r}\text { Patient }(\mathrm{n}=57) \\
(\text { mean } \pm \text { SD) }\end{array}$ & $\begin{array}{c}\text { Control }(\mathrm{n}=51) \\
(\text { mean } \pm \text { SD })\end{array}$ & P-value \\
\hline $\begin{array}{l}\text { Calcium corrected } \\
(\mathrm{mmol} / \mathrm{L})\end{array}$ & $2.2 \pm 0.2$ & $2.4 \pm 0.3$ & 0.002 \\
Phosphate $(\mathrm{mmol} / \mathrm{L})$ & $1.4 \pm 0.2$ & $1.3 \pm 0.3$ & $\mathrm{NS}$ \\
Alk phosphatase $(\mathrm{u} / \mathrm{L})$ & $110.1 \pm 46.7$ & $76.4 \pm 33.9$ & 0.0001 \\
Urinary calcium & $0.04 \pm 0.03$ & $0.02 \pm 0.02$ & 0.008 \\
$\begin{array}{l}\text { Excretion } \\
\text { Urine Ca/Creatinine Ratio }\end{array}$ & $0.38 \pm 0.27$ & $0.24 \pm 0.21$ & 0.005 \\
\hline
\end{tabular}

The mean BMD T-Scores for patients and controls was within normal. There was no significant difference between the patients and controls (P-value $=$ 0.24) (Table 3).

\section{Table 3}

Bone mineral density values for the sub-sample of patients and controls

\begin{tabular}{lccc}
\hline $\begin{array}{l}\text { BMD n=24 } \\
\text { T-score }\end{array}$ & Patient $(\mathrm{n}=24)$ & Control & P-value \\
\hline $\begin{array}{l}\text { Mean ( } \pm \text { SD) } \\
\text { Median (range }-\end{array}$ & $1.8 \pm 0.9$ & $1.4 \pm 1.3$ & 0.24 \\
\begin{tabular}{l}
1.16 to 4.19$)$ \\
\hline
\end{tabular} & 1.6 & 1.1 & \\
\hline
\end{tabular}

\section{DISCUSSION}

Osteoporosis is a common condition with major public health and economic implications (12). A number of risk factors have been proposed like age, female sex, estrogen deficiency, low calcium intake and also, exposure to anti-convulsant medication (13). In this study, women of reproductive age on anti-epileptic
Bone biochemical abnormalities previously described in people on medication for epilepsy include hypocalcaemia, hypophosphataemia, and elevated serum alkaline phosphatase $(15,16)$. In this study there was a significant reduction of calcium in patients compared with controls. In the assumed absence of confounders such as malnutrition, this reflected osteomalacia or increased bone turnover which has long been a recognised consequence of hepatic enzyme induction of vitamin D metabolism by anti-convulsants.

There were also significantly higher values of alkaline phosphatase, urinary calcium excretion and urine calcium creatinine ratio among the patients than among controls. Serum bone alkaline phosphatase is elevated with increased osteoblastic activity and hence is a marker of bone formation. Serum bone alkaline phosphatase is also an inducible enzyme and the fact that a vast majority of patients were on enzyme inducing drugs could have pushed up the serum levels.

On the other hand, increased urinary excretion of calcium and urine calcium creatinine ratio imply an increase in osteoclastic bone resorption. These combined findings may therefore be a reflection of 
increased bone loss. These were findings in contrast to Erbayat et al. (17) who found significantly lower urinary calcium levels in children on valproic acid and carbamazepine than in controls. His reasons for this finding were not elucidated.

The serum phosphate difference, though not significant, showed a marginally higher value among the patients. This may suggest an underlying hyperparathyroidism and hypovitaminosis D as a mechanism of AED-associated bone disease in this population, however these were not assessed in this study.

Quantitative Computerised Tomography (CT) measurement of spine bone density has similar accuracy as Dual X-ray Absorptiometry (DEXA) in experienced hands (18) and this was the method of BMD assessment used in this study. The diagnosis of osteoporosis and osteopenia according to the WHO guidelines, are based on the T-score. The Z-score can occasionally be helpful if it is very abnormal as it suggests a secondary cause of osteoporosis. In this study Z-score was not assessed, and this may have affected the accuracy of the results considering most of the patients $(72 \%)$ were in the 20 to 29 year age bracket.

There was no significant difference in the Bone Mineral Density of the lumbar spine between patients and controls. Patients in fact had a higher mean Bone Mineral Density than controls, which is probably a chance finding.

There was, therefore, discordance between biochemical and radiological findings in this study. Possible reasons for this discordance include the small sample size in which differences between groups would likely be missed. A possible lag time between biochemical and radiological changes may be another explanation for the discordance. For anti-epileptic drug induced bone changes, biochemical differences can show as early as three months after the insult, whereas radiological changes are seen between one and three years after the insult, if DEXA is used (19). This is a finding also noted in oncological studies, where biochemical markers predicts the appearance of bone metastasis with varying lead times (20). This would suggest that in our group, biochemical changes may have manifested much earlier than the radiological changes, and it may be a matter of time before the radiological changes became clinically evident.

Alternatively, the choice of site for Bone Mineral Density assessment may also contribute to this difference in biochemical and radiological findings. Stephen et al. (21) showed a significantly reduced bone density in post-menopausal women at the femoral neck, but not at the lumbar spine in the same group. In fact, at the lumbar spine, his female patients had better bone mineral density findings than the controls. His finding brought to the fore the possibility of greater bone mineral density differences in the appendicular (cortical bone of the appendages) and not the axial skeleton, in post-menopausal women. In the peri-menopausal women, however, it has been suggested that the lumbar spine may be a more sensitive indicator of bone loss, which is why it was the site of choice in this study (22).

Another likely reason for the discordance is the issue of seizure control. More than half the patientshad inadequate seizure control which may be attributed to poor drug compliance. With this inadequate level of compliance, obvious changes expected as early as one year onto therapy may take longer to become evident, because the offending drug is not achieving sufficient serum levels to cause clinically significant side effects.

There were a number of limitations to this study. This was a small sample size and hence differences between groups could have been missed. It was also difficult to exclude all the confounders that could influence a woman's bone health, some of which were difficult toassessobjectively, likediet, exercisestatusand co-morbidity. Also drug dosages were not considered and may have contributed to the severity of the side effects. Lastly, compliance was not assessed objectively and was based on patient history and file records.

\section{ACKNOWLEDGEMENTS}

To the patients and controls for agreeing to participate in this study. To Mr. Mwangi, Mrs. Murimi and Mr. Oyugi for carrying out the lab tests, patient recruitment and statistical analysis. Mr. Wachira, Chief Radiographer, Nairobi Hospital, and to The Kenyatta National Hospital Ethics and Research Committee who permitted this publication.

\section{REFERENCES}

1. Kwan, P. and Brodie, M.J. Early identification of refractory epilepsy. N. Engl. J. Med. 2000; 342: 314319.

2. LaRoche, S.M. and Helmers, S.L. Thenew antiepileptic drugs. JAMA. 2004; 291: 605-614.

3. Morrell, M.J., Sarto, G.E., Osborne, Shafer. P. et al. Health issues for women with epilepsy: a descriptive survey to assess knowledge and awareness among healthcare providers. J. Women's Health Gend. Based Med. 2000; 9: 959-965.

4. Farhat, G., Yamout, B., Mikati, M.A. et al. Effect of antiepileptic drugs on bone density in ambulatory patients. Neurology. 2002; 58: 1348-1353.

5. Valimaki, M., Tiihonen, M., Laitinen, K. et al. Bone mineral density measured by Dual- energy x-ray absorptiometry and novel markers of bone formation and resorption in patients on AEDs. J. Bone Miner Res. 1994; 9: 631-637.

6. Sheth, R., Wesolowski, C., Jacob, J. et al. Effect of Carbamazepine and Valproate on bone mineral density. J. Pediatr. 1995;127: 256-262. 
7. Chung, S. and Ahn, C. Effects of AED therapy on bone mineral density in ambulatory epileptic children. Brain Dev. 1994; 16: 382-385.

8. Pack, A.M. and Morrell, M.J. Adverse effects of antiepileptic drugs on bone structure: epidemiology, mechanisms and therapeutic implications. CNS Drugs. 2001; 15: 633-642.

9. Pack, A.M. The association between antiepileptic drugs and bone disease: Review article. Epilepsy Currents. 2003; 3: 91-95.

10. Weinstein, R.S., Bryce, G.F., Sappington, L.J. et al. Decreased serum ionized calcium and normal vitamin D metabolite levels with anticonvulsant treatment. J. Clin. Endocrinol. Metab. 1984; 58: 1003-1009.

11. Odawa, F., Ojwang, S., Muia, N. et al. The prevalence of post menopausal osteoporosis in black Kenyan women. J. Obs. Gyn. Eastern and Cent. Afr. 2004; 17 Suppl 1: abstract 37.

12. Walker-Bone, K., Arden, K. and Cooper, C. Epidemiological aspects of osteoporosis. Reviews Contemporary Pharmaco. 1998; 9: 225-231.

13. Cummings, S., Nevitt, M., Browner, W. et al. Risk factors for hip fractures in white women. N. Eng. J. Med. 1995; 332: 767-773.

14. Munyoki, G.M., Kwasa, T.O., Newton, C.R. and Amayo, E.O. The prevalence of epilepsy in a malaria endemic region of Kenya. MMed dissertation, University of Nairobi, 2005.

15. O'Hare, J.A., Duggan, B., O'Driscoll, D. et al. Biochemical evidence for osteomalacia with Carbamazepine therapy. Acta. Neurol. Scand. 1980; 62: 282-286.
16. Gough, H., Goggin, T., Bissessar, A. et al. A comparative study of therelativeinfluenceofdifferentanticonvulsant drugs vs. exposure and diet on vitamin $\mathrm{D}$ and calcium metabolism in outpatients with epilepsy. Q.J.M. (New series 59) 1986; 230: 569-577.

17. Erbayat Altay, E., Serdaroglu, A., Tumer, L. et al. Evaluation of bone mineral metabolism in children receiving Carbamazepine and Valproic acid.J. Pediatr. Endo. Metab. 2000; 13: 933-939.

18. Henderson, K.E., Baranski, T. J. and Bickel, P.E. The Washington Manual endocrinology subspecialty consult.; 2005 edition: 138-154.

19. Endres, D.B. and Rude, R.K. Mineral and bone metabolism in Tietz textbook of clinical chemistry3rd edition; Burtis CA, Ashwood RE (Ed); WB Saunders Company. 2005:1936.

20. Frenay, M., Namer, M., Boublil, J.L. et al. Value of urinary hydroxyproline and bone isoenzyme of alkaline phosphatise in the early detection and follow up of bone metastasis in breast cancer patients. Bull. Cancer. 1988; 75: 533-539.

21. Stephen, L.J., McLellan, A.R., Harrison, J.H. et al. Bone density and antiepileptic drugs: A case-controlled study. Seizure. 1999; 8: 339-342.

22. Timperlake, R.W., Cook, S.D., Thomas, K.A. et al. Effects of anticonvulsant drug therapy on bone mineral density in a paediatric population. J. Pediatr. Orthop. 1988; 8: 467-470. 